\title{
Warning Compulsive Behavior Preceding Acute Ischemic Stroke
}

\author{
Norbert Nighoghossian $^{a} \quad$ Lili Zeng $^{a} \quad$ Laurent Derex $^{a, b}$ Serkan Cakmak ${ }^{a} \quad$ P. Trouillas ${ }^{a}$ \\ ${ }^{a}$ Cerebrovascular Unit, ${ }^{b}$ Creatis UMR 5515, Inserm 630, Hôpital Neurologique Pierre Wertheimer, Lyon, France
}

Dear Sir,

Abrupt onset of compulsive behavior (CB) without other neurologic or psychiatric signs or symptoms rarely precedes an acute stroke. We describe 2 young women who developed an acute $\mathrm{CB}$ followed by an ischemic stroke. These two cases raise concern about the need to promptly perform the appropriate brain imaging studies in patients who develop acute $\mathrm{CB}$ without neurological signs or symptoms or history of psychiatric disease.

\section{Case 1}

A 42-year-old, right-handed woman was brought to the emergency department on April 21, 2005, because she was compulsively doing housework during the night. She had no history of psychiatric disease. On admission, her neurological examination was normal. She was well oriented, her speech was focused on cleaning activities, and she explained endlessly to the physician how to clean a bathroom. After the clinical examination, she resumed her compulsive activity with an incredible need to clean the medical office and she could not be reasoned with. On April 22, as the compulsive cleaning activity went on with no relief, she was compelled to move to the psychiatric department. Routine biological tests and toxicology screening involving the search of cocaine, cannabis or amphetamines were negative.
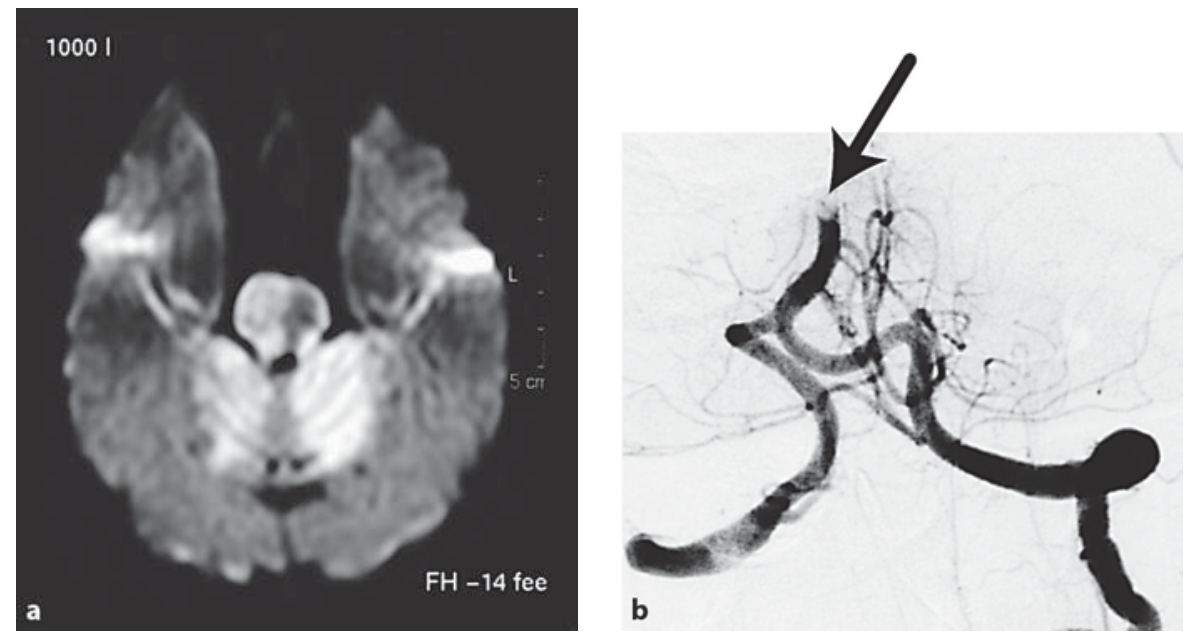

Fig. 1. a Diffusion-weighted imaging showing cerebellar and middle pons ischemia. b MRA: mid-basilar occlusion.

On April 23, at 8:00, she developed a deep comatose state with tetraplegia. She was admitted at 13:00 to our intensive care unit. Multimodal stroke MRI with diffusion-weighted imaging revealed multiple cerebellar infarctions and brainstem involvement. Magnetic resonance angiography (MRA) showed a mid-basilar thrombosis (fig. 1).
Despite an aggressive intra-arterial approach, she was not recanalized and died 2 days later.

Case 2

A 26-year-old, right-handed woman, without risk factors or past history of psychiatric or neurological disorders, suddenly developed, on May 22, 2005, a

\section{KARGER}

Fax +4161306 1234 E-Mail karger@karger.ch www.karger.com (c) 2006 S. Karger AG, Basel 0014-3022/06/0561-0039\$23.50/0

Accessible online at:

www.karger.com/ene
Norbert Nighoghossian

Hôpital Neurologique Pierre Wertheimer

59 Bd Pinel, FR-69003 Lyon (France)

Tel. +33 47235 7810, Fax +33 472357806

E-Mail norbert.nighoghossian@chu-lyon.fr 

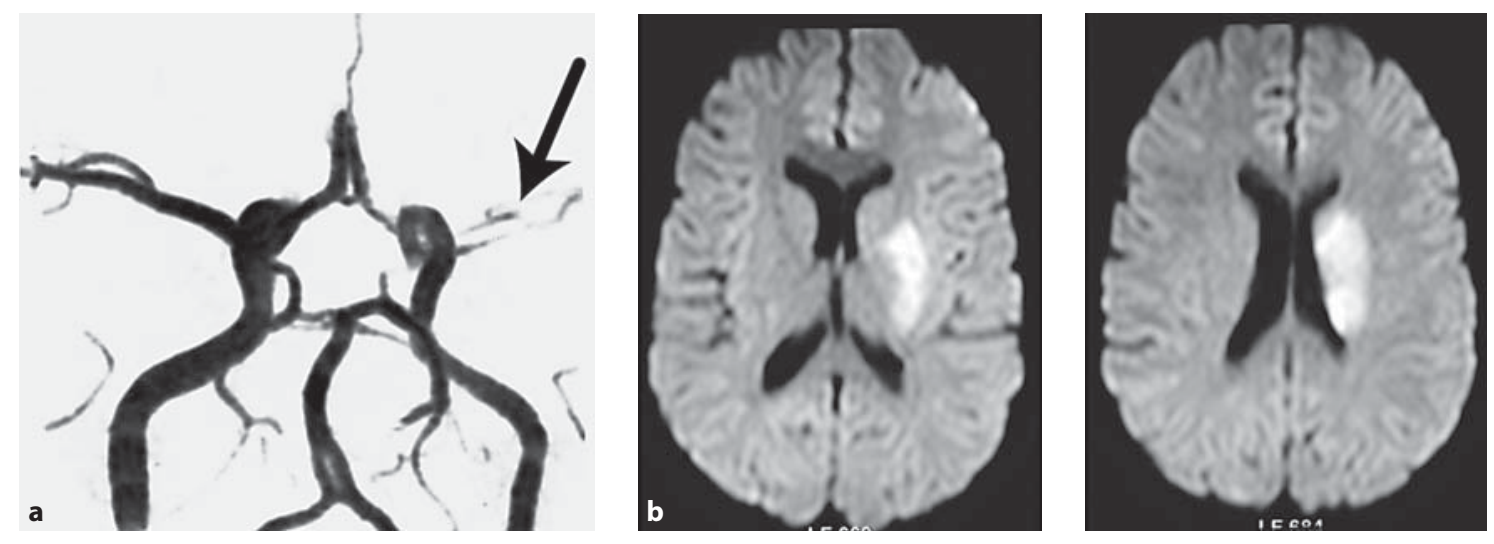

Fig. 2. a Proximal left middle cerebral artery occlusion. b Left lenticulostriate infarction.

strange behavior while she was in a night club. She took recurrent photographs of people who were there, and the next morning she took multiple pictures of her house windows. She told her boyfriend that she had an incredible need to take pictures and her speech was focused on her camera. Twenty-four hours later, she developed an acute mutism, and was compelled to move to the psychiatric department. Routine biological tests and toxicology screening involving the search of cocaine, cannabis or amphetamines were negative. On May 24, she developed an acute right hemiplegia and was admitted to our stroke unit. Neurological examination noted a dense right hemiplegia associated with a global aphasia. Diffusion-weighted MRI showed a deep left middle cerebral artery infarction involving lenticular nucleus and corona radiata (fig. 2). MRA showed a left proximal middle cerebral artery occlusion. She was treated with intravenous t-PA. She experienced a good recovery and 10 days later, she had a mild nonfluent aphasia. Neurovascular and biological screening including the search of autoimmune disease or vasculitis was negative; accordingly, the stroke was considered cryptogenic.

\section{Discussion}

CB occurs usually later after stroke [13]. The link between the onset of $\mathrm{CB}$ and stroke occurrence is only speculative. Indeed, the onset of CBs can be observed in the age range of the 2 patients, and the as- sociation with stroke could be coincidental. Toxicological screening failed to identify any factors favoring either $\mathrm{CB}$ or stroke. Moreover, the abrupt course of the disease in both cases did not allow an exhaustive cognitive testing; therefore, subtle neuropsychological deficits consistent with alarming brain damage may have been missed. In case 1, the etiology of stroke remained unknown, as we could not rule out a specific vasculitis such as lupus disease. Moreover, autopsy was not performed. In case 2, stroke was considered cryptogenic as we did not reveal any autoimmune processes such as vasculitis or a cardiembolic source.

To date, most neuroanatomic theories of CB have implicated structures involved in response feedback and emotional regulation. Neurophysiologic dysfunction in the frontal lobes, the basal ganglia/limbic striatal and thalamocortical circuits, and their interconnections with limbic structures, might be implicated [4].

In $\mathrm{CB}$, the availability of brain serotonin transporters may be reduced in the midbrain/brainstem [5]. Other findings suggest that the dopaminergic neurotransmitter system of the basal ganglia could be involved in the pathophysiology of CB [6]. The ischemic injury in our patients may have involved both systems. Acute $\mathrm{CB}$ rarely precedes ischemic stroke and the relationship between the two is mainly speculative. Nevertheless, patients with no history of psychiatric disorders or neurological symptoms, and in whom $\mathrm{CB}$ is associated with an uncontrollable need to repetitively perform the same task, with an inability to recognize their unusual behavior, should undergo a brain imaging assessment including brain CT or MRI.

\section{References}

1 Swoboda KJ, Jenike MA: Frontal abnormalities in a patient with obsessive-compulsive disorder: the role of structural lesions in obsessive-compulsive behaviour. Neurology 1995;45:2130-2134.

2 Simpson S, Baldwin B: Neuropsychiatry and SPECT of an acute obsessive-compulsive syndrome patient. Br J Psychiatry 1995; 166: 390-392.

3 Carmin CN, Wiegartz PS, Yunus U, Gillock KL: Treatment of late-onset OCD following basal ganglia infarct. Depress Anxiety 2002; 15:87-90.

4 Modell SC, Mountz JM, Curtis GC, Greden JF: Neurophysiologic dysfunction in basal ganglia/limbic striatal and thalamocortical circuits as a pathogenic mechanism of obsessive-compulsive disorder. J Neuropsychiatry Clin Neurosci 1986;9:357-381.

5 Stengler-Wenzke K, Muller U, Angermeyer MC, Sabri O, Hesse S: Reduced serotonin transporter-availability in obsessive-compulsive disorder (OCD). Eur Arch Psychiatry Clin Neurosci 2004;254:252-255.

$6 \mathrm{Kim} \mathrm{CH}$, Koo MS, Cheon KA, Ryu YH, Lee JD, Lee HS: Dopamine transporter density of basal ganglia assessed with (123I) IPT SPET in obsessive-compulsive disorder. Eur J Nucl Med Mol Imaging 2003;30:1637-1643. 